\title{
RANCANG BANGUN SISTEM INFORMASI KESEHATAN GIZI ANAK DAN PEREMPUAN PADA KELOMPOK PUTRI KARTINI DESA LUBUK LAGAN SELUMA BARAT KABUPATEN SELUMA
}

\author{
Eko Suryana'), Achmad Fikri Sallaby²) \\ 1)2)Fakultas Komputer, Universitas Dehasen \\ Jln. Meranti No. 32, Bengkulu-Indonesia, \\ Email : ekosuryana@unived.ac.id ${ }^{1}$, fikrisallaby@unived.ac.id ${ }^{2)}$
}

\begin{abstract}
ABSTRAK
Sistem informasi merupakan suatu "tools" yang dapat digunakan, dalam pemanfaatan yaitu untuk mengelola data atau informasi yang lebih baik dalam konteks memberikan gambaran distribusi status gizi dengan faktor penyebab secara terintegrasi guna pengambilan keputusan yang tepat. Analisis dilakukan dengan proses penggabungan dari faktor-faktor penyebab status gizi secara tumpang susun (overlay). Beberapa faktor akan di kaji untuk mengetahui pengaruhnya terhadap permasalahan status gizi di wilayah tersebut. Kelompok Putri Kartini adalah sebuah Lembaga Swadaya Masyarakat yang memiliki komitmen dan perhatian terhadap tingkat kesehatan masyarakat terutama fokus terhadap gizi anak dan pemberdayaan perempuan yang ada di Desa Lubuk Lagan bekerjasama dengan Dinas Kesehatan dan Pemerintah Daerah Kabupaten Seluma Barat guna dapat memberikan informasi yang valid. Untuk mengatasi persoalan yang dihadapi mitra akan dibekali dengan kemampuan membuat dan menggunakan sistem informasi berbasis komputer guna mengenali faktor-faktor penyebab gizi buruk anak dan perempuan di Desa Lubuk Lagan Kecamatan Seluma Barat sehingga tidak lagi melakukan pendataan dan pemetaan penyebab gizi buruk secara manual seperti yang masih dilakukan saat ini dan semua data akan tersimpan dengan baik.
\end{abstract}

Kata kunci : Sistem Informasi, gizi, anak dan perempuan, komputer

\section{PENDAHULUAN}

Kondisi di Desa Lubuk Lagan Kecamatan Seluma Barat Kabupaten Seluma saat ini mempunyai permasalahan pada kesehatan, gizi anak dan pemberdayaan perempuan dimana cukup tingginya pernikahan usia dini. Salah satu faktor turunnya kualitas kesehatan dan gizi pada anak adalah tingginya pernikahan usia dini pada daerah tersebut. Hal ini terjadi dikarenakan pasangan yang menikah usia dini pada desa tersebut masih belum siap secara ekonomi, ibu muda yang belum siap secara psikologis untuk mengurus bayinya yang berdampak luas ke tingkat kekerasan dalam rumah tangga dan tingkat perceraian yang cukup tinggi di desa Lubuk Lagan. Jumlah kematian bayi pada profil kesehatan tahun 2013 sebanyak 7 dari jumlah (3.181) bayi lahir hidup atau dengan angka kematian yang dilaporkan 2 per $1000 \mathrm{KH}$. Bila dibandingkan dengan tahun-tahun sebelumnya, ada penurunan kematian secara signifikan. Jumlah kematian anak balita sebanyak 2 orang dari jumlah $3.181 \mathrm{KH}$, atau dengan angka 0,6 (1) orang, jumlah kematian ibu berjumlah 4 orang dari angka kelahiran hidup (Dinkes Kabupaten Seluma).

Kelompok Putri Kartini adalah sebuah Lembaga Swadaya Masyarakat yang memiliki komitmen dan perhatian terhadap tingkat kesehatan masyarakat terutama fokus terhadap gizi anak dan pemberdayaan perempuan yang ada di Desa Lubuk Lagan bekerjasama dengan Dinas Kesehatan dan Pemerintah Daerah Kabupaten Seluma Barat guna dapat memberikan informasi yang valid

Sistem informasi sesungguhnya adalah sebuah sub sistem yang merupakan bagian dari sebuah sistem lain yang lebih besar. Sistem informasi tidak dapat dirancang dan dioperasikan secara terpisah dari sub sistem yang lain (Lipurasri Anastasia, 2013). 
Dalam merancang antarmuka menggunakan pendekatan 7C (Context, Content, Community, Customization, Communication, Connection, Commerce) (Kosasi Sandy, 2014)

Informasi dalam lingkup sistem informasi memiliki beberapa ciri yaitu (Zaenal Sekty Wijaya, 2015:3):

a. Baru, informasi yang didapat sama sekali baru dan segar bagi penerima.

b. Tambahan, informasi dapat memperbaharui atau memberikan tambahan pada informasi yang telah ada.

c. Korektif, informasi dapat menjadi suatu koreksi atas informasi yang salah sebelumnya.

\section{METODE}

Metode penelitian yang digunakan dalam penelitian ini adalah metode pengembangan sistem model waterfall. Model Waterfall merupakan salah satu model pengembangan perangkat lunak yang ada di dalam model SDLC (Sequencial Development Life Cycle) (Firmansyah Yoki dan Udi, 2018).

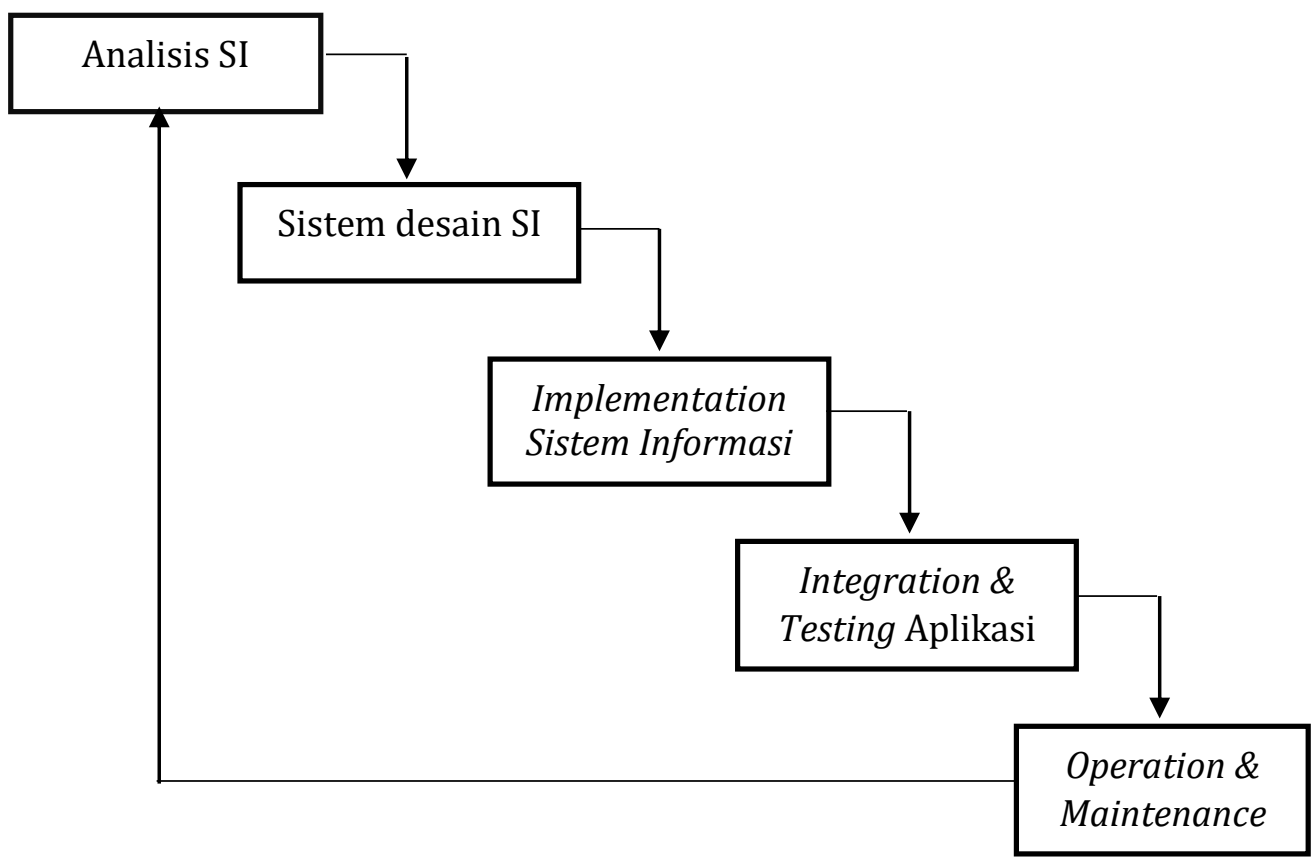

Gambar 1. Model Pengembangan Sistem Informasi

\subsection{Analisis Sistem informasi}

Sistem yang akan dibangun dianalisa terlebih dahulu mengenai data yang akan diolah menjadi informasi, sehingga sistem yang dibangun bisa sesuai dengan kebutuhan kelompok Kartini dalam menampilkan informasi.

1. Sistem desain Sistem Informasi

Setelah tahap analisis, dilakukan desain sistem sesuai dengan kebutuhan. Desain rancangan aplikasi dibuat berdasarkan data informasi kesehatan gizi anak dan perempuan Desa Lubuk Lagan Seluma Barat kabupaten Seluma.

2. Implementasi sistem informasi

Tahap ini dimana sistem yang telah didesain dan dibangnu, kemudian dijalankan atau dicoba terlebih dahulu apakah terjadi error atau tidak sebelum dioperasikan.

3. Operasi dan maintenance

Aplikasi sistem dijalankan oleh user secara langsung dan dilakukan pemeliharaan jika sistem aplikasi membutuhkan update. 


\section{HASIL DAN PEMBAHASAN}

Implementasi sistem merupakan tahap meletakkan sistem sehingga siap untuk dioperasikan.Implementasi bertujuan untuk mengkonfirmasi modul-modul perancangan, sehingga pengguna dapat memberi masukan kepada pengembangan sistem (Hengki Tamando Sihotang, 2017).

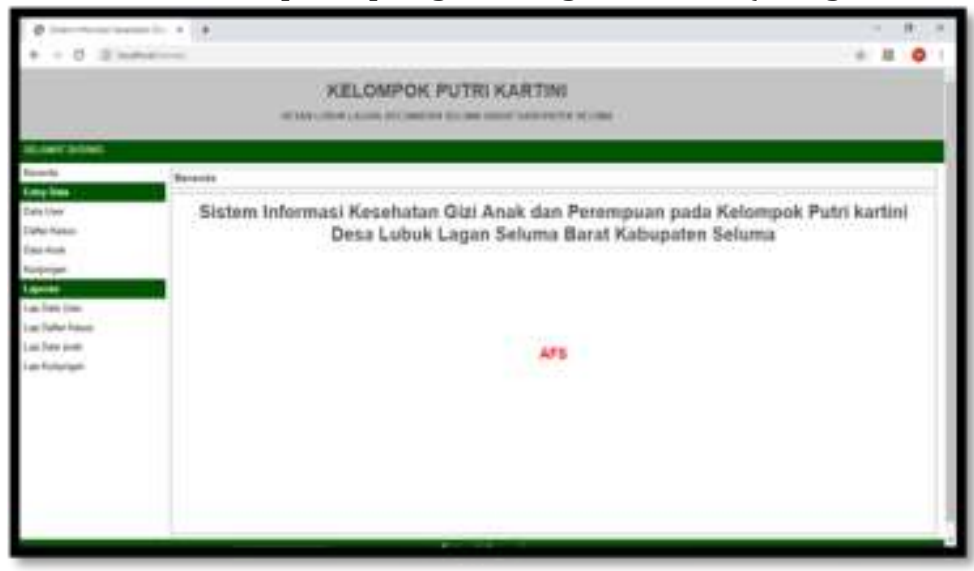

Gambar 2. Menu Index Sistem Informasi Kelompok Kartini

Menu index merupakan tampilan awal ketika sistem aplikasi pertama kali dibuka. Pada menu ini user dapat meilhat data user, daftar kasus dan daftar kunjungan.

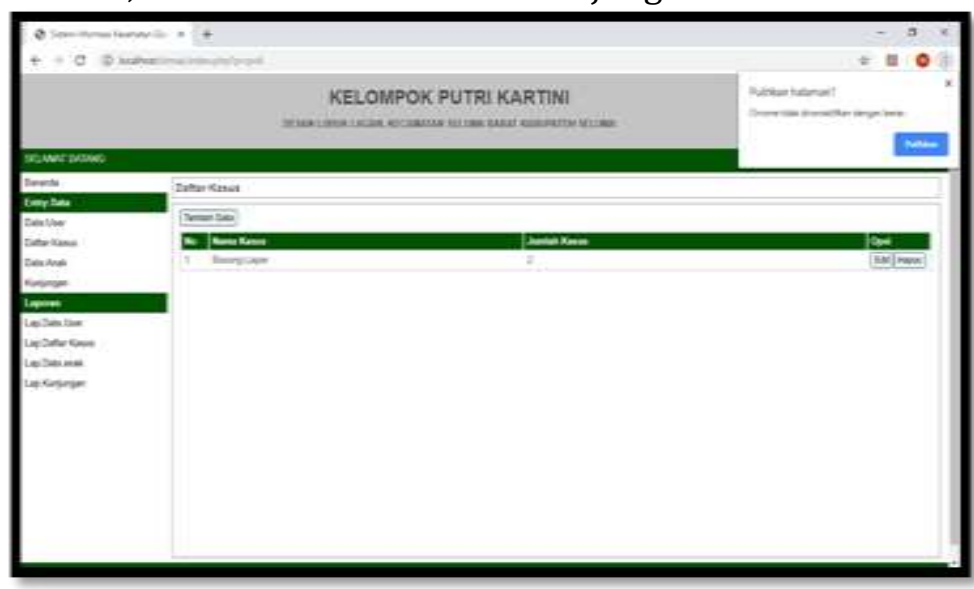

Gambar 3. Tampilan Data Kasus

Tampilan data kasus merupakan data kasus yang terjadi di desa Lubuk Lagan. Pada menu ini di tampilkan daftar kasus yang terjadi dan jumlah korban.

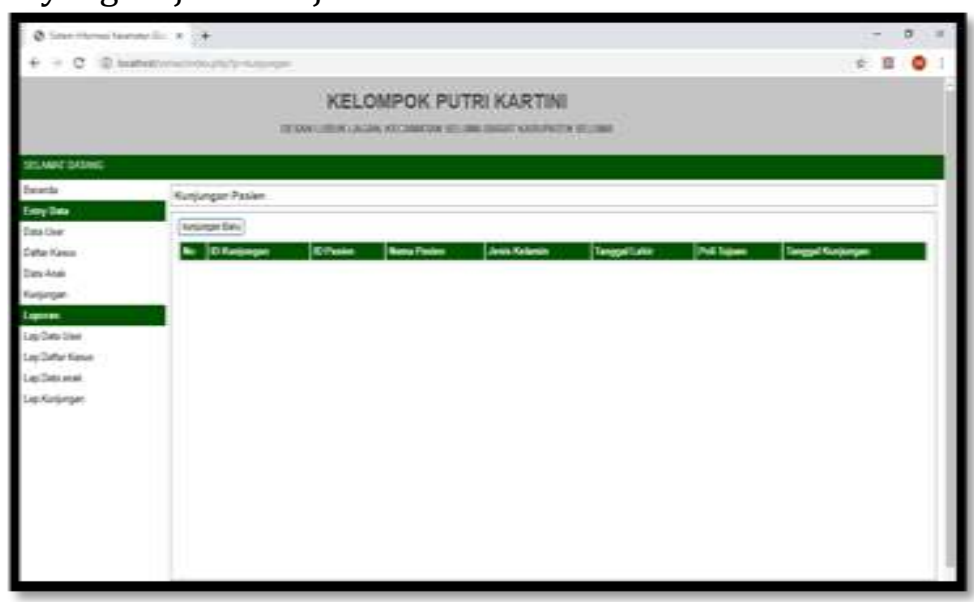

Gambar 4. Daftar Kunjungan Pasien

Tampilan ini merupakan tampilan daftar kunjungan pasien yang melaporkan kasus yang di alami dan di input oleh user. Sistem informasi ini di kelola hanya oleh user. 


\section{PELAKSANAAN PENGABDIAN}

Setelah aplikasi sistem informasi selesai dibuat, maka selanjutnya adalah melakukan sosialisasi penggunaan aplikasi Sistem Informasi Kesehatan Gizi Anak dan Perempuan. Hal ini penting dilakukan agar sistem informasi yang dibuat mampu digunakan dengan baik sesuai dengan kebutuhan.

Kegiatan sosialisasi dilaksanakan pada tanggal 27 Juli 2019 di Posyandu Desa Lubuk Lagan yang diikuti oleh Ketua, Pendamping dan anggota Kelomlpok Putri Kartini.

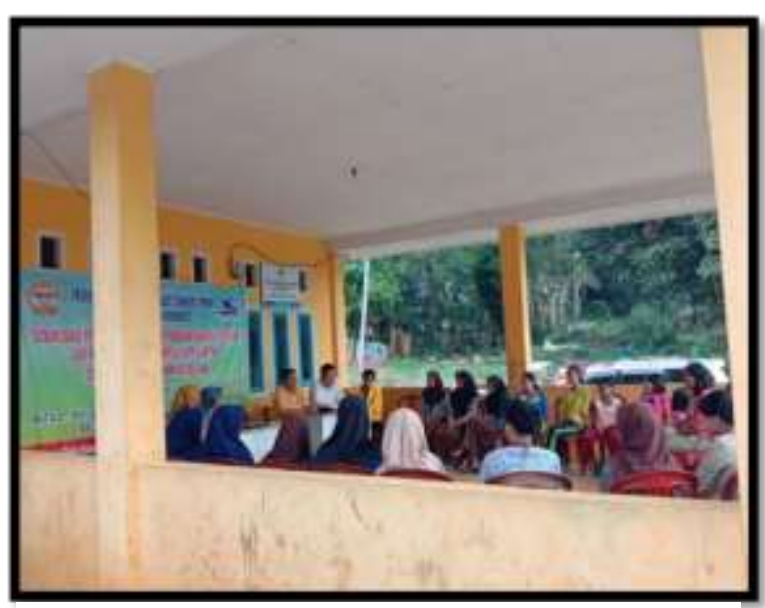

Gambar 3. Kegiatan Sosialisasi

Dilakukan di Posyandu Ds. Lubuk Lagan

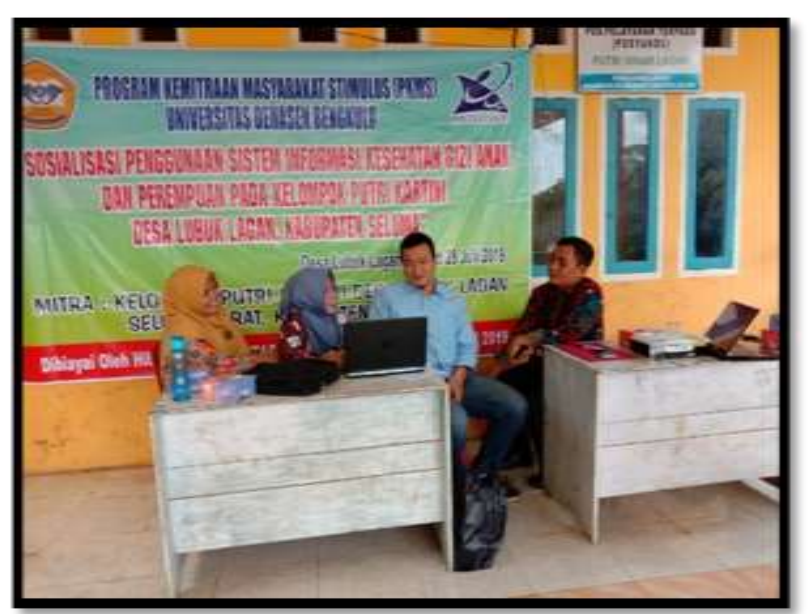

Gambar 4. Ketua dan Pendamping Kelompok Putri Kartini Secara Antusias Belajar Penggunaan Aplikasi

\section{SIMPULAN DAN REKOMENDASI}

Sistem informasi ini di buat bertujuan untuk menampilkan informasi kesehatan gizi anak dan perempuan di desa Lubuk Lagan, Kecamatan Seluma Barat Kabupaten Seluma provinsi Bengkulu. Di harapkan sistem informasi ini bisa dikembangkan lagi.

\section{ACKNOWLEDGEMENTS}

Kegiatan Penelitian ini dibiayai oleh Hibah PKMS Ditlitabmas Kemenristek Dikti Tahun 2019.

\section{DAFTAR PUSTAKA}

Anastasia Lipursari, 2013. Peran Sistem Informasi Manajemen (Sim) Dalam Pengambilan Keputusan, Semarang: STIE Semarang.

Zaenal Sekti Wijaya, 2015. Penerapan Sistem Informasi Berbasis Komputer Pada Aplikasi Monitoring Keuangan Dan Aset (Terkait Penatausahaan Piutang Tuntutan Ganti Kerugian Negara). Magister Akuntasi Universitas Sebelas Maret. Surakarta

Hengki Tamando Sihotang, 2017. Perancangan Aplikasi Sistem Pakar Diagnosa Diabetes Dengan Metode Bayes. STMIK Pelita Nusantara.Medan (38)

Sandy Kosasi, 2014. Pembuatan Sistem Informasi Penjualan Berbasis Web Untuk Memperluas Pangsa Pasar, Pontianak: Program Studi Sistem Informasi, STMIK, Pontianak

Yoki Firmansyah \& Udi, 2018. Penerapan Metode SDLC Waterfall Dalam Pembuatan Sistem Informasi Akademik Berbasis Web Studi Kasus Pondok Pesantren Al-Habi Sholeh Kabupaten Kubu Raya, Kalimantan Barat. Program Studi Manajemen Informatika AMIK BSI, Pontianak 